Allergic reaction to prick tests with fruit juice

\begin{tabular}{ll}
\hline Test substance & Reaction at 20 minutes \\
\hline Mango juice & $\begin{array}{l}2 \cdot 7 \mathrm{~cm} \text { Wheal with } 5 \cdot 2 \mathrm{~cm} \text { spur and } \\
\text { surrounding erythema }\end{array}$ \\
$\begin{array}{l}1: 10 \text { Mango:physiological saline } \\
2 \cdot 0 \mathrm{~cm} \text { Wheal } \\
0.8 \mathrm{~cm} \text { Wheal } \\
\text { Melon juice }\end{array}$ & No reaction \\
\hline
\end{tabular}

\section{Comment}

Mangoes belong to the family Anacardiaceae, which includes cashew nuts, pistachio nuts, hog plum, Jamaican plum, sumac, and poison ivy. The leaves, stems, and pericarp of the fruit contain uroshiol and cardol and other substances known to be sensitisers, $\beta$ pinene and limonene. $\beta$ Pinene and limonene are known to cause allergic contact dermatitis mediated by a type IV delayed hypersensitivity mechanism. Contact dermatitis in children after climbing mango trees has been reported, and erythematous vesicular

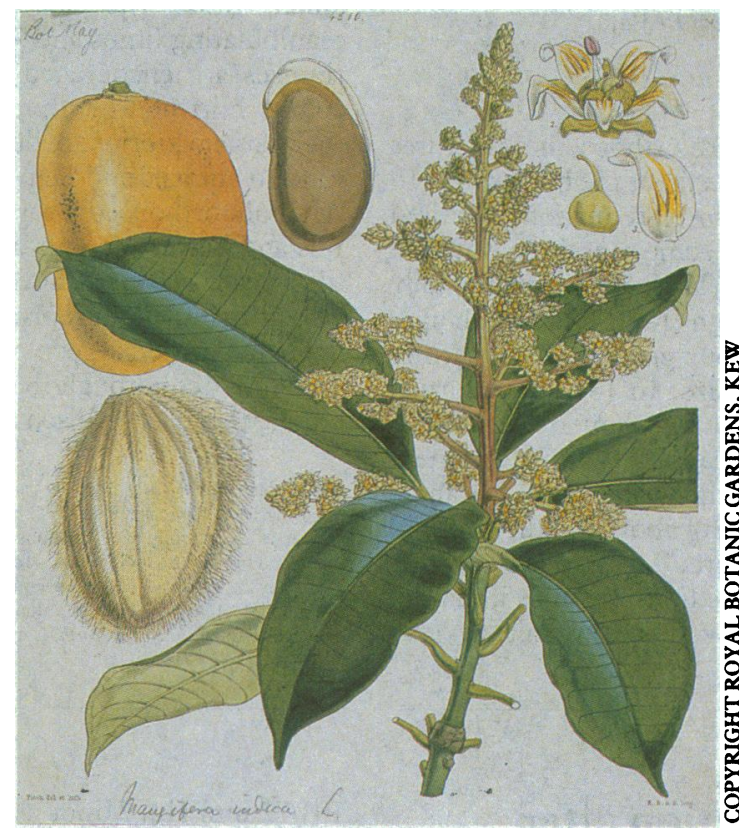

Mangifera indica, the mango eruptions of the lips and face after ingestion of mango skin were first described in $1939 .{ }^{2}$ Our patient, however, probably had a type I immediate hypersensitivity reaction despite the negative result of the radioallergosorbent test. An anaphylactic reaction to ingestion of fruit is rare, though urticarial reactions after ingestion of strawberries, oranges, and tomatoes are well known and the same reactions to exotic fruits such as kiwi fruit and pawpaw have also been described. We found only two reports of anaphylactic reaction after ingestion of mangoes. ${ }^{34}$

Immediate hypersensitivity is presumed to be mediated by IgE and seems to be more common in atopic people. A second mechanism caused by short term anaphylactic antibodies of type IgG4 has been described, 5 but in association with contact urticaria rather than generalised anaphylaxis, and contact sensitisers are probably different from those causing an IgE response. The negative result of the radioallergosorbent test in this case may have been due to lack of sensitivity of the test rather than anaphylaxis mediated by another class of immunoglobulin ( $R \mathbf{H}$ Champion, personal communication).

This case is interesting as the patient was a professional fruiterer, and despite having eaten many exotic fruits such as kiwi fruit, pawpaw, lychees, and muscadines, he had never eaten mangoes or other members of the Anacardiaceae before. He had a history of atopy, and several cases of anaphylaxis related to food have been reported in people with atopy. Reactions to exotic fruits are rare in the northern hemisphere, but with increasing importation of unusual food they may become more common. Eating unusual food should be considered as a cause of anaphylaxis or milder allergic reactions, and the allergen should be identified so that it may be avoided.

We thank Dr M Davies, consultant dermatologist, Plymouth General Hospital.

Douglas HMG, Nater JP. Histamine in foods causing false positive scratch tests. F Allergy Clin Immunol 1968;42:164-7.

Zakon SJ Contact dermatitis due to mango fAMA 1939;113:1808.

3 Rubin JM, Shapiro J, Muehlbauer P, Grolnick M. Shock reaction following ingestion of mango. FAMA 1965;193:397-8.

Dang RW, Bell DB. Anaphylactic reaction to the ingestion of a mango. Hawaii Med f 1967;27:149-50.

5 Pigatto PD, Riva F, Altomare GF, Parotelli R. Short-term anaphylactic antibodies in contact urticaria and generalized anaphylaxis to apple. Contact Dermatitis 1983;9:511.

\title{
Rat catcher's warfarin treatment associated with rectal haemorrhage
}

\section{R M Kirby, L J Lawson}

North Staffordshire Royal Infirmary, Stoke on Trent R M Kirby, FRCS, senior registrar in surgery

L J Lawson, FRCS, consultant surgeon
We report on a patient who developed rectal bleeding after self treatment with warfarin.

\section{Case report}

A 66 year old retired pest controller was admitted after presenting to casualty with rectal bleeding of acute onset. On examination he had a low rectal tumour. A biopsy confirmed carcinoma, and he was treated by abdominoperineal resection two weeks after his initial presentation. Postoperatively he admitted to a sequence of events that he had previously withheld. He had developed dizzy spells three weeks before his presentation and thought that these indicated a likely stroke. To lessen the chances of this event he started to treat himself with warfarin from stocks of rat poison that he had kept after his retirement; on alternate days he dipped his wet finger into the powder and then sucked it. He stopped the treatment as soon as the rectal bleeding began and was wary of admitting to it on presentation. His prothrombin time was not measured on admission but was normal by the time he had confessed to his therapeutic endeavours.

\section{Comment}

Anticoagulation may cause bleeding from several sources if not correctly regulated. Poisoning with unprescribed warfarin is not uncommon. We think that this set of circumstances is unusual; in view of the lack of proof of a prolonged prothrombin time we assume that his ingestion of warfarin precipitated the rectal bleeding. His wife subsequently destroyed all remaining stocks. 